\title{
DEDICATED EXHAUST GAS RECIRCULATION IN SPARK IGNITION ENGINES
}

\author{
Sooraj Rehan ${ }^{1}$ \\ 1 Department of Mechanical Engineering, Michigan Technological University, Houghton, Michigan, USA, \\ 49931, e-mail: srehan@mtu.edu
}

Received: 2017.02.03

Accepted: 2017.03.06

Published: 2017.06.01

\begin{abstract}
The impact of high levels of exhaust gas recirculation (EGR) has been well documented to decrease fuel consumption and reduce emissions of spark ignition engines. But there are also many limitations associated with this technology like EGR control and tolerance, which can reduce the potential efficiency improvements. A new concept called D-EGR has been presented in which the exhaust from a sub group of power cylinders is channeled back to the intake of all the cylinders. In this literature review both experimental and numerical analysis of this technology is shown. In the former case experiments were performed on 2.0 L PFI engine with gasoline as a fuel in part and high load conditions and the results show that at part loads the D-EGR engine can lead to lower Brake Specific Fuel Consumption, lower HC and CO emissions and higher brake thermal efficiency. At high load operations the results show improved combustion stability and superior knock tolerance. In the numerical studies it shows comparable thermal efficiency with conventional spark ignition (SI) engines and reduction in $\mathrm{NO}_{\mathrm{X}}$ emissions.
\end{abstract}

Keywords: exhaust gas recirculation, NOx emissions, spark ignition engines.

\section{INTRODUCTION}

The ever going race of improving fuel economy and reducing emissions has led to number of new technologies being invented and tested worldwide. Current SI engine technologies which are in production include but not limited to direct injection, downsizing with turbochargers or superchargers and hybridization. One alternate way is to dilute the incoming charge with fresh air or exhaust gases from the engine. It is well proven that lean burn in SI engines offer more efficiency but this may lead to more $\mathrm{NO}_{\mathrm{X}}$ emissions. Cooled EGR is a promising technology which can lead to higher efficiency as it leads to increased indicated cycle efficiency and reduced heat transfer and throttling losses. It is because of the fact that EGR gases have a high specific heat capacity and it also works a diluent in combustion process. This lead to lower in-cylinder gas temperatures. It further improves efficiency by increasing the ratio of specific heats during cycle. With high levels of EGR reduction in $\mathrm{NO}_{\mathrm{x}}, \mathrm{CO}, \mathrm{PM}$ and $\mathrm{PN}$ emissions has also been noticed.

There are also some challenges associated with cooled EGR which include but not limited to misfire, stability of combustion, EGR flow control and engine component durability. With increasing the dilution levels of EGR burn velocities are decreased which can lead to unstable engine operation or misfire. To overcome these shortcoming while maintaining or exceeding the efficiency Dedicated EGR has been introduced.

\section{D-EGR}

D-EGR is an engine configuration in which the exhaust from one sub group of power cylinders is channeled back to the intake of all the cylinders i.e. creating EGR for all cylinders with the exhaust of a few. In the case of four cylinder 


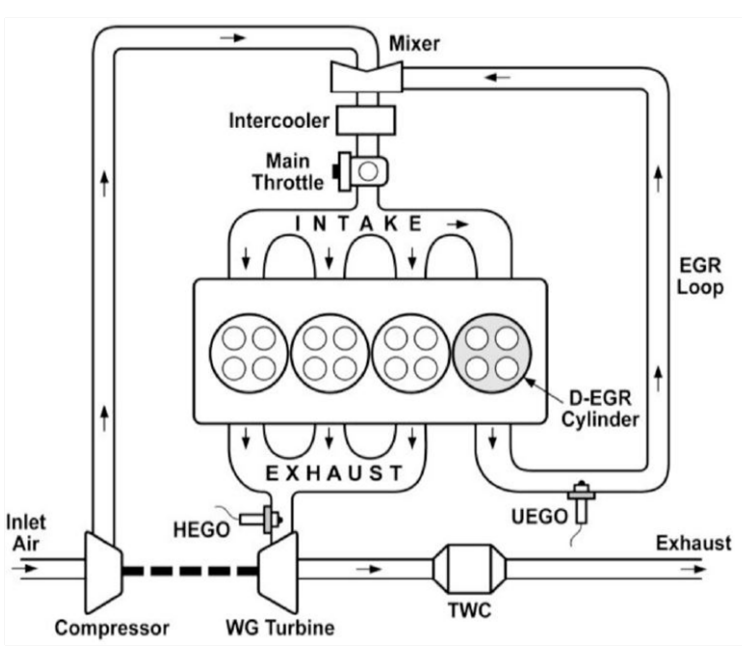

Fig. 1. Layout of turbocharged 4-cylinder engine in D-EGR configuration

engines, the exhaust of one cylinder is used as an EGR for the entire test engine which leads to stable EGR value of $25 \%$. So, the need for active EGR control across the speed load range is minimized. This also increases the range of equivalence ratio of the dedicated EGR cylinder to run as its exhaust will never exit the engine before passing through other cylinders. So, D-EGR cylinder can be run rich and produce more $\mathrm{H}_{2}$ and $\mathrm{CO}$ due to incomplete combustion. These two gases act as reformate for other cylinders and also helps to recover some waste heat which is generally rejected to atmosphere while still generating power in the dedicated cylinder. The presence of reformate enhances the flame speed, combustion and knock tolerance of all the cylinders and therefore can overcome the limitations of SI engines at higher EGR levels. Even in the low pressure loop EGR, by adding bottled reformate, the performance of D-EGR can be simulated. Other cylinders in the meanwhile can be run on stoichiometric air-fuel ratios which means that a three-way catalyst can be utilized to reduce pollutant emissions. Figure 1 shows the schematic of a D-EGR engine set up.

\section{LPL EGR AND D-EGR AT PART LOAD OPERATION}

\section{Experimental Set up}

In this study a turbocharged four cylinder 2.0 $\mathrm{L}$ engine with port fuel injection is used. In its baseline configuration, it produced a peak torque of $300 \mathrm{~N}-\mathrm{m}$ at $2250 \mathrm{rpm}$ and maximum power of $180 \mathrm{hp}$ at $5500 \mathrm{rpm}$. The original compression ra- tio of the engine was 9.1:1 which was increased to $12.5: 1$ and $13.5: 1$. The engine was made to run on different EGR values in low pressure loop and also with dedicated EGR with various equivalence ratios for dedicated cylinder which led to a nominal EGR value of $25 \%$ for rest of the cylinders. To make it possible to compare the above mentioned configurations both of these set up used identical engine long block, boosting and fueling hardware as well as ignition system.

\section{Brake Specific Fuel Consumption}

In Figure 2, Brake specific fuel consumption is shown for different cases of LPL EGR and DEGR at $2000 \mathrm{rpm} / 2$ bar BMEP. The labels inside the columns represent the cyclic variability of IMEP for each engine configuration. The equivalence ratio was kept constant for dedicated cylinder at $\Phi_{\mathrm{D}}=1.3$. Reduction in BSFC was mainly due to improved combustion which in turn could depend on various factors. There was substantial decrease in BSFC when $25 \%$ cooled EGR was used in baseline engine configuration as is clear from the difference between first and second column. The next major reduction was for D-EGR case which was due to significantly higher combustion stability due to high quality EGR. The increase in BSFC for D-EGR in fourth column was because no EGR mixer was used which lead to uneven supply of EGR to different cylinders which was also the reason for increase in $\mathrm{CoV}$.

\section{Emissions}

The variation in emissions of various exhaust gases with respect to $\Phi_{\mathrm{D}}$ is shown in figure 3. It is evident from the graph that with increase in $\Phi_{D}$,

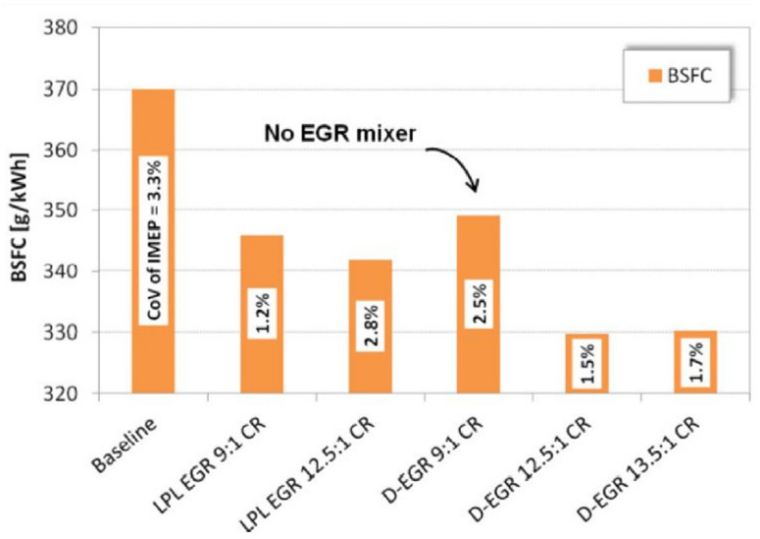

Fig. 2. BSFC for various LPL and D-EGR configuration at $2000 \mathrm{rpm} / 2$ bar BMEP with $\Phi_{\mathrm{D}}=1.3$ 


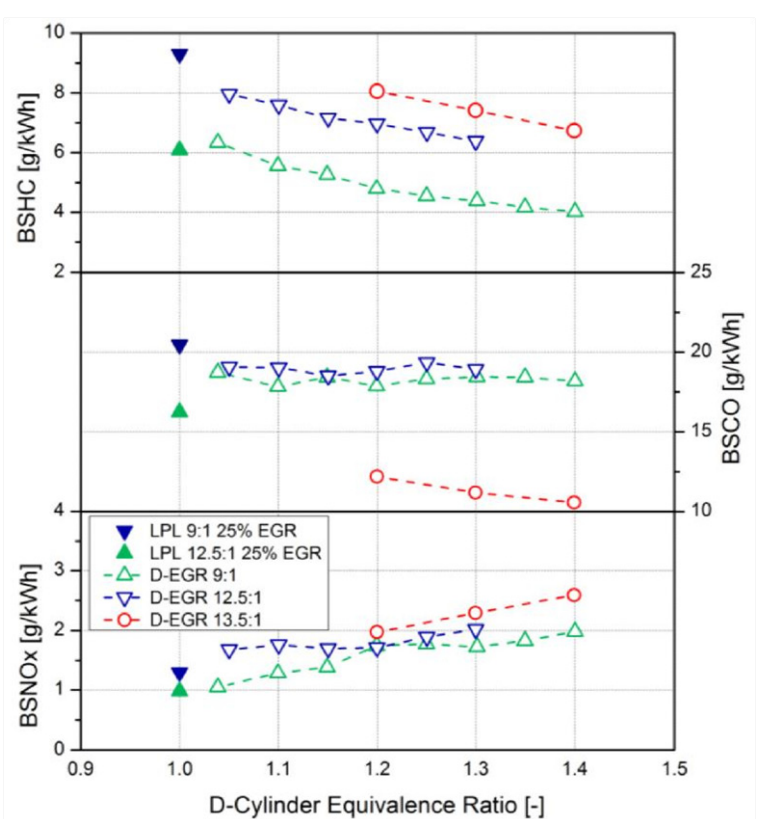

Fig. 3. D-EGR engine out emissions as a function of $\Phi_{\mathrm{D}}$ at $1250 \mathrm{rpm} / 3.5$ bar BMEP

BSHC was reduced for all compression ratios. In general, higher CR test showed higher BSHC due to crevice loading effect. Brake Specific $\mathrm{CO}$ was relatively unaffected with change in $\Phi_{D}$ but it was significantly lower for 13.5:1 CR. $\mathrm{BSNO}_{\mathrm{X}}$ emissions were almost doubled owing to higher incylinder temperatures which was due to increase in amount of $\mathrm{H}_{2}$ and $\mathrm{CO}$ in the exhaust of dedicated cylinder with increase in $\Phi_{\mathrm{D}}$ but these were still $1 / 4$ that of a non-dilute engine.

\section{Brake Thermal Efficiency}

The variation in BTE and $\mathrm{CoV}$ at different part load conditions is shown in figure 4. Generally, the main efficiency improvements were due to cooled EGR and higher CR in LPL configuration.

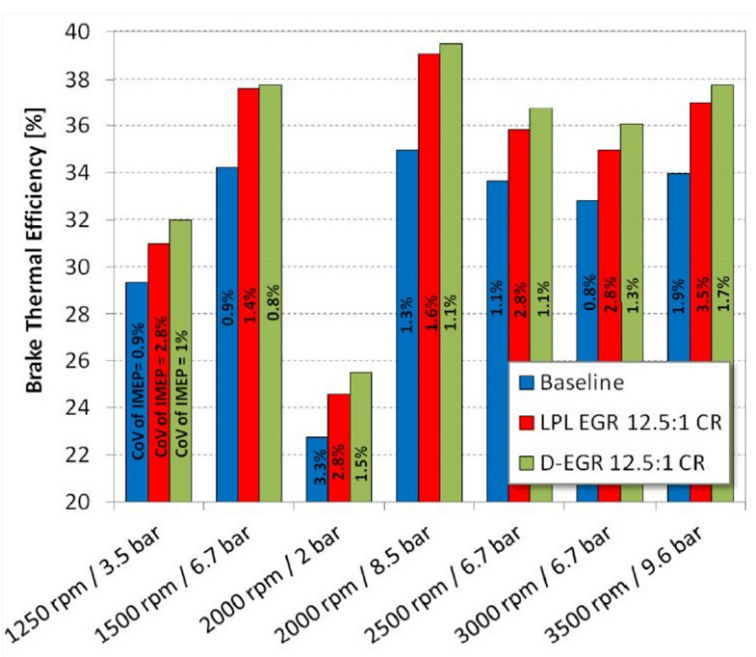

Fig. 4. Brake thermal efficiencies comparison at various part load conditions

Although, D-EGR set up showed higher BTE for all cases but its impact was less significant as compared to LPL EGR. Also, CoV was always lower in D-EGR due to stable EGR supply.

\section{LPL EGR AND D-EGR AT HIGH LOAD OPERATION}

\section{Experimental Set up}

The same engine set up was used in this case but the operations were conducted for higher loads.

\section{Combustion Stability}

The BSFC for D-EGR and LPL EGR configurations at $2500 \mathrm{rpm}$ is shown in figure 5. All the tests were conducted for a constant CR of 12.5:1. As BSFC primly depend upon combustion, it is

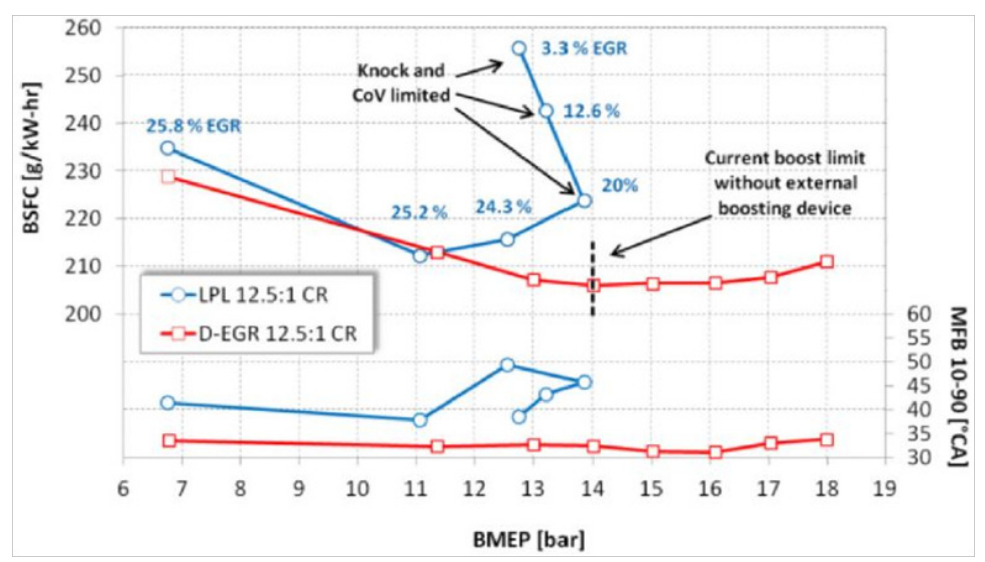

Fig. 5. Load sweep at $2500 \mathrm{rpm}$ with 12.5:1 CR 


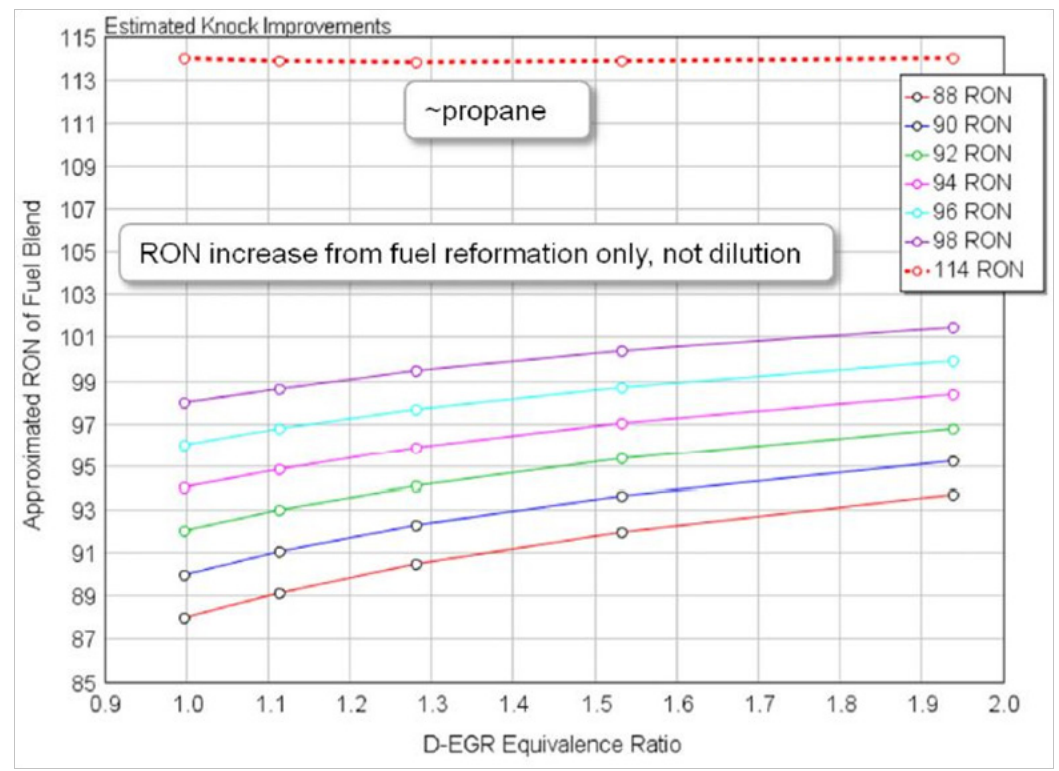

Fig. 6. Predicted RON increase with $\Phi D$ based on component blends

apt to analyze combustion stability on a BSFC graph. The stability requirement in this case was to maintain the cyclic variation of less than $5 \%$ in IMEP. It can be seen that at low loads i.e. 6-7 bar, D-EGR engine configuration had better BSFC as compared to LPL EGR due to improved engine stability and combustion efficiency. At mid loads i.e. 11 bar BMEP there was small difference between the BSFC values of both cases as the engine was running at optimal combustion phasing with good stability and combustion efficiency in both LPL EGR and D-EGR. The most notable difference was found at higher engine loads i.e. above 11 bar where D-EGR improved combustion efficiency whereas LPL EGR engine came to its inherent combustion limitations. As is clear from the graph at 12.5 bar BMEP, EGR has to be reduced from less than $25 \%$ because of stability limit with spark retard. However, D-EGR engine could sustain 18 bar load due to high quality of EGR.

\section{Impact of $\Phi_{D}$ on RON}

The main reason why D-EGR leads to higher knock tolerance and better combustion can be seen by comparing the RON of the exhaust gas coming out of the dedicated cylinder. This is the result of a different simulation study conducted as part of same research by Gingrich et al. In figure 6 the impact of $\Phi_{D}$ on RON is shown. As can be seen with increase in the $\Phi_{D}$ RON increased this was because of the fact that $\mathrm{H}_{2}$ and $\mathrm{CO}$ both have 120 and 108 RON (approx.) ratings respectively as compared with gasoline which has $91 \mathrm{RON}$. As $\Phi_{\mathrm{D}}$ is increased more $\mathrm{H}_{2}$ and $\mathrm{CO}$ was produced in dedicated cylinder due to incomplete combustion and these gases acts as a fuel reformate for other cylinders. Apart from this, $\mathrm{H}_{2}$ also leads to higher laminar flame burning velocities and higher flame temperature thus avoiding the main problem with EGR i.e. partial burn and misfire.

\section{Engine Operating Map LPL EGR vs D-EGR}

To graphically represent the improvements possible with D-EGR concept, full operating map of LPL EGR and D-EGR configuration with 12.5:1 CR is shown in Figure 7. The red region at the top of the figure represents the region that

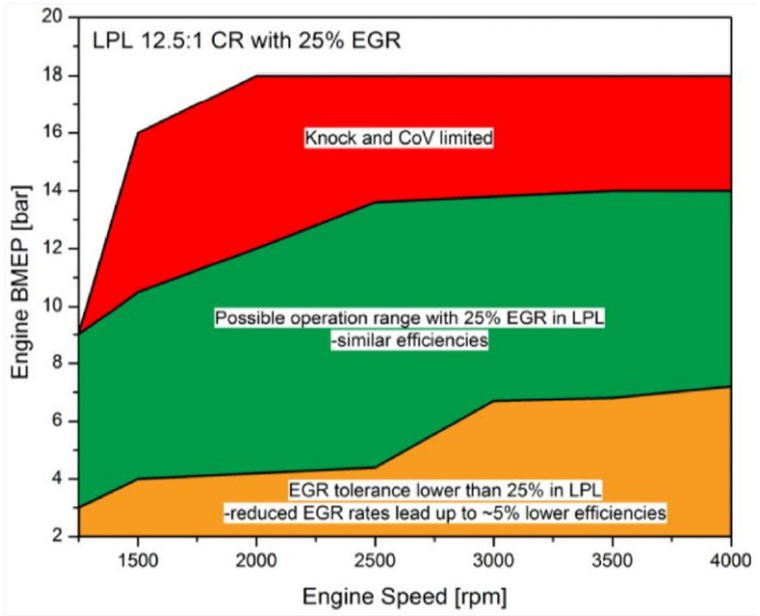

Fig. 7. Engine operating map in the LPL EGR setup with $25 \%$ EGR 
could not be accessed in LPL EGR case due to knock and CoV of IMEP limitations but was accessible in D-EGR configuration with proper boost system. The yellow zone at the bottom represents the area where operation with LPL EGR was not possible due to combustion instability which increases potential of partial burn or misfire. This region can be accessed with lower EGR but with BSFC penalty of up to $5 \%$. Only in the middle green part LPL EGR configuration was capable of operating with 25\% EGR and comparable efficiency to D-EGR.

Due to limitation of current review paper, quantitative impact of $\mathrm{H}_{2}$ and $\mathrm{CO}$ on in-cylinder combustion process is not discussed in detail. However, it is evident beyond doubt that these gases improve combustion, the direct result of which can be seen in improved BSFC and lesser $\mathrm{CoV}$.

\section{D-EGR NUMERICAL ANALYSIS WITH NATURAL GAS}

\section{Analysis Method}

In this study a numerical analysis of a SI engine was performed. The assumed SI engine had bore of $82 \mathrm{~mm}$, stroke length of $64 \mathrm{~mm}$ and CR of 10.76. The calculation of laminar burning velocity was done at adiabatic conditions. The $\Phi$ for D-cylinder was assumed to vary from 0.6-3.4 and number of engine cylinders were assumed to vary from 3 to 6 that were run with the exhaust from dedicated cylinder and fresh air and fuel equivalence ratios of 0.6-1. The fuel selected was methane which had $90 \%$ natural gas. To calculate the engine work and heat release rate Weibe function was used. Combustion duration in Weibe function was assumed by function of turbulent burning velocity that was proportional to laminar burning velocity. Calculation of heat loss was done by Woschini function. Turbulent flow was not considered in this case and the temperature of cylinder wall was assumed to be $498.15 \mathrm{k}$. Due to brevity of space detailed equations are not shown.

\section{Thermal Efficiency}

Total thermal efficiency of all cylinders i.e. 1-4 as a function of equivalence ratio of cylinder 1 is shown in figure 8. Cylinders 2-4 were run on stoichiometric conditions while the $\Phi_{\mathrm{D}}$ was varied from 0.6-3.4. Inlet Temperature was assumed to be $298.15 \mathrm{k}$ and inlet pressure was considered

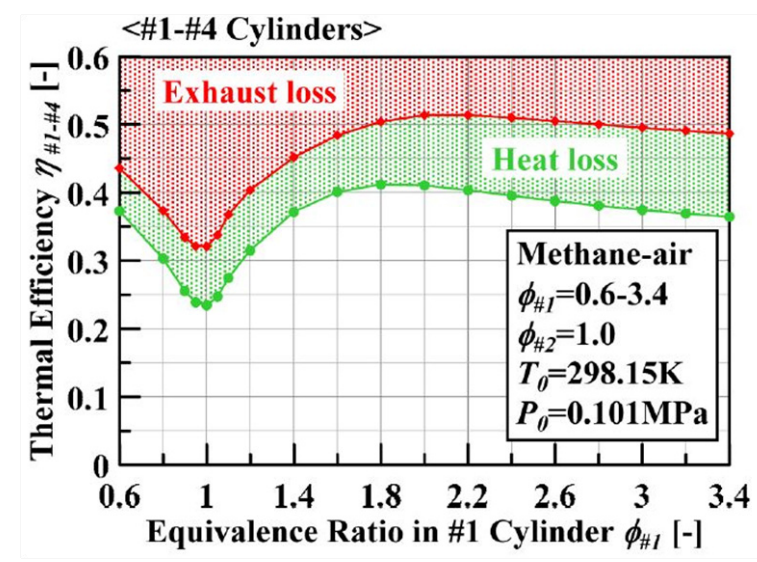

Fig. 8. Total thermal efficiency in the SI engine

as $0.101 \mathrm{MPa}$. It is evident from the graph that the net thermal efficiency increased when $\Phi_{\mathrm{D}}$ was increased from 0.6 to 1.6. At $\Phi_{\mathrm{D}}=2.2$ thermal efficiency of the concept engine was highest. This seemed to be due to increase in $\mathrm{H}_{2}$ concentration in the dedicated exhaust stream with increase in $\Phi_{D}$. However, flame temperature also increased because of $\mathrm{CO}$ that promotes laminar burning velocity like $\mathrm{H}_{2}$ does but also causes little increase in temperature which leads to heat losses. Therefore, maximum thermal efficiency after considering heat losses occurred at $\Phi_{\mathrm{D}}=1.8$. It is reasonable to expect that if there is a way to reduce heat loss to the cylinder walls maximum thermal efficiency will occur at $\Phi_{\mathrm{D}}=2.2$.

\section{$\mathrm{NO}_{\mathrm{x}}$ Concentration in Exhaust Gases}

To show the impact of D-EGR on $\mathrm{NO}_{\mathrm{X}}$, six different cases of D-EGR composition were simulated to compute the $\mathrm{NO}_{\mathrm{X}}$ concentration in the final exhaust gases coming out of the engine. These six cases are shown in table 1 . All the cylinders were run on stoichiometric conditions except cyl-

Table 1. Calculation Conditions

\begin{tabular}{|c|c|c|l|c|}
\hline Case & $\begin{array}{c}\text { D-EGR } \\
\text { ratio } \\
\text { (number of } \\
\text { cylinders) }\end{array}$ & \multicolumn{2}{|c|}{ Equivalence ratio } & $\begin{array}{c}\text { Thermal } \\
\text { efficien- } \\
\text { cy (\%) }\end{array}$ \\
\hline $1^{*}$ & no EGR (4) & \multicolumn{2}{|c|}{$\Phi=1.0$} & 36.0 \\
\hline 2 & no EGR (4) & \multicolumn{2}{|c|}{$\Phi=0.8$} & 41.7 \\
\hline 3 & $\gamma=0.2(6)$ & $\Phi_{\# 1}=1.6$ & $\Phi_{\# 2+\# 6}=1.0$ & 41.9 \\
\hline 4 & $\gamma=0.25(5)$ & $\Phi_{\# 1}=1.6$ & $\Phi_{\# 2-\# 5}=1.0$ & 41.7 \\
\hline 5 & $\gamma=0.33(4)$ & $\Phi_{\# 1}=1.8$ & $\Phi_{\# 2-\# 4}=1.0$ & 41.2 \\
\hline 6 & $\gamma=0.5(3)$ & $\Phi_{\# 1}=2.0$ & $\Phi_{\# 2-\# 3}=1.0$ & 38.4 \\
\hline$*$
\end{tabular}




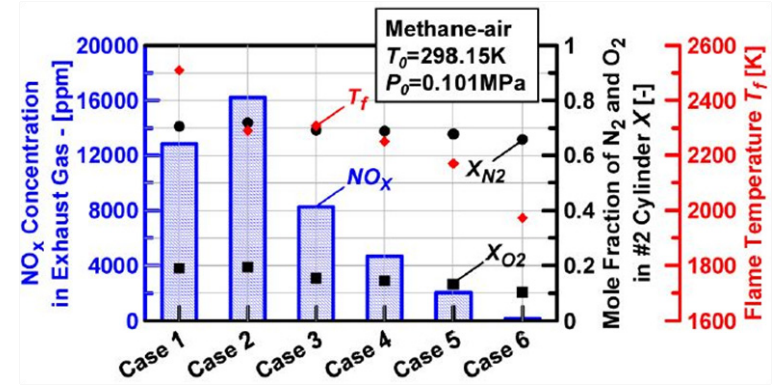

Fig. 9. NOX concentration in exhaust gas varied by the calculation

inder 1 where $\Phi_{\mathrm{D}}$ was varied from 1.6 to 2 . Also in case 1 and 2, no EGR was used.

The NOx emissions along with flame temperature for the six cases are shown in figure 9. The flame temperature was maximum for case 1 as in this case stoichiometric $\mathrm{A} / \mathrm{F}$ ratio was provided which lead to complete combustion whereas in case 2 although flame temperature was lower than case 1 but it had higher $\mathrm{NO}_{\mathrm{X}}$ emissions due to excessive $\mathrm{O}_{2}$. which reacted with $\mathrm{N}_{2}$ to form $\mathrm{NO}_{\mathrm{x}}$.

For cases 3-6 reduction in $\mathrm{NO}_{\mathrm{X}}$ concentration was observed with increasing D-EGR, this was due to the fact that dilution effect of $\mathrm{CO}_{2}$ and $\mathrm{H}_{2} \mathrm{O}$ was becoming more prominent with increasing EGR. At the same time the amount of premixed air and fuel intake reduced, which lead to decrease in heat release rate and hence lower temperatures. The decrease in the inlet mixture meant decrease in $\mathrm{N}_{2}$ and $\mathrm{O}_{2}$ intake in each cycle which further deceased the $\mathrm{NO}_{\mathrm{X}}$ concentration and this phenomenon intensified as the increase of EGR ratio. It is noteworthy that thermal efficiencies were more than $41 \%$ and $\mathrm{NO}_{\mathrm{X}}$ emissions less than $8100 \mathrm{ppm}$ when nominal D-EGR was less than 0.33 . The last case with 3 cylinders although showed least $\mathrm{NO}_{\mathrm{X}}$ but it was estimated that the flame temperature becomes too low to operate engine stably.

\section{CONCLUSIONS}

As this is still a nascent technology to corroborate the same type of results from different research institutions is not entirely possible but it can be said with confidence that with D-EGR technology some of the limitations of EGR can be corrected. There is one area where study number 1 and 3 do not fully agree, the first study shows overall reduction in exhaust emission but little increase in $\mathrm{NO}_{\mathrm{x}}$ emissions whereas the third study shows large reduction in $\mathrm{NO}_{\mathrm{x}}$ emissions with increasing the D-EGR values. This discrepancy may due to the fact that the latter work is a simulation study where many hypothetical cases like $\Phi_{\mathrm{D}}>$ 1.7 are considered which may not be practical due to physical limitations of the engine hardware.

- All the above studies confirm that with $\Phi_{D}>$ 1.2 , load range for stable combustion can be enhanced by using D-EGR concept.

- The HC and CO emissions are reduced with increasing $\Phi_{\mathrm{D}}$ values as is predicted by the simulation as well as experimental studies.

- The main point at which all the studies agree is that thermal efficiency is improved by increasing D-EGR values.

- Second study shows wider range of engine BMEP operation with increasing values of $D$ EGR.

- Second study also proves that $\mathrm{H}_{2}$ and $\mathrm{CO}$ acts as fuel reformate which is seen by increase in the $\mathrm{RON}$ ratings.

\section{Abbreviations}

AFR - Air Fuel Ratio

BMEP - Brake Mean Effective Pressure

BSCO - Brake Specific Carbon Monoxide

BSFC - Brake Specific Fuel Consumption

BSHC - Brake Specific Hydrocarbons

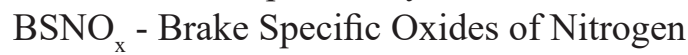

BTE - Brake Thermal Efficiency

$\mathrm{CO}$ - Carbon Monoxide

$\mathrm{CoV}$ - Coefficient of Variance

CR - Compression Ratio

D-EGR - Dedicated Exhaust Gas Recirculation

ФD-Dedicated Cylinder Equivalence Ratio

EGR - Exhaust Gas Recirculation

HC - Hydrocarbon

IMEP - Indicated Mean Effective Pressure

LPL - Low-Pressure Loop

$\mathrm{NO}_{\mathrm{x}}$ - Oxides of Nitrogen

PFI - Port Fuel Injected

PM - Particle Matter

PN - Particle Number

RON - Research Octane Number

SI - Spark Ignited

\section{REFERENCES}

1. Heywood John B., Internal Combustion Engine Fundamentals, McGraw-Hill, Inc., 1988, ISBN: 0-07028637-X. 
2. Alger, T. and Mangold, B., Dedicated EGR: A New Concept in High Efficiency Engines, SAE Int. J. Engines 2(1):620-631, 2009, doi:10.4271/200901-0694.

3. Gingrich, J., Gukelberger, R., Alger, T., and Mohan, V., In-cylinder Fuel Reformation for High EGR Dilution SI Engines, SIA International Conference and Exhibition, The Spark Ignition engine of the Future, 2013.

4. Gukelberger, R., Gingrich, J., Alger, T., Almaraz, S. et al., LPL EGR and D-EGR $®$ Engine Concept
Comparison Part1: Part Load Operation, SAE Int. J. Engines 8(2):2015, doi:10.4271/2015-01-0783.

5. Gukelberger, R., Gingrich, J., Alger, T., and Almaraz, S., LPL EGR and D-EGR ${ }^{\circledR}$ Engine Concept Comparison Part 2: High Load Operation, SAE Int. J. Engines 8(2):2015, doi:10.4271/2015-01-0781.

6. Lee,S.,Ozaki,K., Iida, N., andSako, T.,APotentiality of Dedicated EGR in SI Engines Fueled by Natural Gas for Improving Thermal Efficiency and Reducing NOx Emission, SAE Int. J. Engines 8(1): 2015, doi:10.4271/2014-32- 0108 . 